\title{
Mitochondrial electron transport activity and metabolism of experimentally bleached hermatypic corals
}

Sylvain Agostini ${ }^{1 *}$, Hiroyuki Fujimura ${ }^{2}$. Hiroyuki Hayashi ${ }^{2}$, Kazuhiko Fujita ${ }^{3}$

${ }^{1}$ Shimoda Marine Research Center, University of Tsukuba, 5-10-1 Shimoda, Shizuoka, Japan

${ }^{2}$ Department of Chemistry, Biology and Marine Science, University of the Ryukyu, 1 Senbaru, Nishihara-cho, Okinawa 903-0213, Japan

${ }^{3}$ Department of Physics and Earth Science, University of the Ryukyu, 1 Senbaru, Nishihara-cho, Okinawa 903-0213, Japan

citation:

Agostini, S., Fujimura, H., Hayashi, H., Fujita, K., 2016. Mitochondrial electron transport activity and metabolism of experimentally bleached hermatypic corals. Journal of Experimental Marine Biology and Ecology 475, 100-107. doi:10.1016/j.jembe.2015.11.012 


\section{Abstract}

Bleached corals (Porites cylindrica and Galaxea fascicularis) were obtained through extended incubation (over 45 days) under light depletion and privation: low light and dark conditions, and heat stress $\left(32^{\circ} \mathrm{C}\right)$. The colonies in the different treatments became bleached and had reduced metabolic rates, photosynthesis, calcification and respiration; reduced biomass, zooxanthellae density, and chlorophyll $a$ concentrations; and reduced mitochondrial electron transport system activity, which represent potential respiration rates. The most important reduction in mitochondrial electron transport activity was shown when the activities were normalized by the unit of surface and not by the unit of host protein. This result indicates that the reduction in activity could be mainly explained by the reduction of biomass and tissue thickness. However, increased Manganese Superoxide dismutase (MnSOD) activity, a mitochondrial SOD, suggests that ROS production occurs in the mitochondria under heat stress with the consequence of potentially damaging the electron transport system. The observed reduced calcification rates observed are hypothesized to be the results of a decrease in the energy available for calcification due to the reduced photosynthetic rates, limiting the availability of substrates for respiration and therefore the energy production, and the decreased in the number of active mitochondrial electron transport system. Electron transport system activity associated with respiration is the basis of all metabolic processes and is not biased by incubation like traditional measurements of respiration in an aquarium. Therefore, ETSA could be used as an overall indicator of coral health, especially for host animal health.

\section{Keywords}

Coral, Bleaching, Mitochondrial activities, Oxidative Stress, Calcification

\section{Highlights}

- Bleached corals, through light depletion and heat stress showed reduced metabolism and mitochondrial electron transport system.

- Reduced respiration and mitochondrial electron transport system activities were associated with reduced calcification rates.

- Reduction in coral biomass and/or direct damage due to reactive oxygen species lead to the reduced mitochondrial electron transport system activities. 


\section{Introduction}

Respiration is the basis of metabolism in animals, including corals. It provides the energy required for all of the subsequent metabolic processes in the form of ATP. Aerobic respiration is divided in two phases: the oxidation of an organic substrate through glycolysis and the citric acid cycle and the reduction of the terminal electron acceptor, oxygen. The transfer of electrons from the reduced cofactors, NADH and FADH2 produced during the oxidation phase is accomplished through a chain of enzymatic transporters embedded in the internal membrane of the mitochondria. Impairment of the mitochondrial machinery, especially the electron transport chain, will have strong repercussions on the respiration process and, subsequently, the metabolism of the organism.

Elevated temperature and other environmental factors can cause coral bleaching: the loss of their photosynthetic symbionts or their pigments (Glynn et al., 1992; Hoeghguldberg and Smith, 1989). The most accepted model for the mechanism of bleaching proposes that it starts with the impairment of the zooxanthellae photosystems (Warner et al., 1999), which leads to the production of reactive oxygen species (ROS) (Higuchi et al., 2010; Jones et al., 1998). However, mitochondria and their electron transport system are also an important source of ROS in animals, and the mitochondrial production of ROS may not be negligible in corals (Downs et al., 2002). This suggests that the importance of the host in the bleaching process may have been underestimated. Recently, Dunn et al. (2012) showed degradation of the host mitochondria in anemone under heat stress. This degradation was associated with the decreased expression of the gene coding for cytochrome c and complex IV, both of which are proteins that are important parts of the mitochondrial electron transport system. Corals incubated in the dark for a long period have also been shown to bleach (Hoegh-Guldberg and Smith, 1989; Tolleter et al., 2013; Yonge et al., 1930). It has been shown that bleached corals have lower calcification rates independently of the cause of bleaching, whether due to heat stress, bacterial factors (Higuchi et al., 2013) or depletion of light. Corals incubated in total darkness for a long period have highly reduced calcification rates with only $10 \%$ of the light calcification rate after $7 \mathrm{~h}$ (Al-Horani et al., 2007).

Photosynthesis and calcification show an intimate relationship at both the community level (Barnes and Chalker, 1990; Gattuso et al., 1996; Kinsey, 1985) and organism level (Allemand et al., 2004; Furla et al., 2000; Moya et al., 2006). The increase in the calcification rates under light for photosynthetic organisms is called light-enhanced calcification. On average, corals show three times higher calcification rates in the light than in the dark. Several hypotheses have been raised to explain this enhancement (these are reviewed in Allemand et al., 2004). Among them, one proposal 
is that $\mathrm{OH}^{-}$resulting from photosynthesis titrate $\mathrm{H}+$ that is formed during the calcification process. For corals, photosynthesis is generally the main source of reduced carbon and is used as combustible for respiration and therefore for the production of the energy required for calcification, which could represent 30\% of the coral's total energy budget (Cohen and Holcomb, 2009). Inhibition of respiration (oxidative phosphorylation) has been shown to inhibit calcification in the light, which then falls to the same level as calcification in the dark (Chalker and Taylor, 1975). In a recent paper (Agostini et al., 2013), the respiration limited calcification model, which support the models by Chalker and Taylor (1975) and, more generally, the Trans-calcification model of McConnaughey (1997) was introduced. In this model the hypothesis made is that calcification in symbiotic corals rates are limited by the energy production through host respiration, itself limited by the ETSA and the amount of substrate for respiration produced by the photosynthetic activity of the symbiont.

Many tools are available to assess the state of the symbionts in corals, such as PAM fluorescence, zooxanthellae density, and pigment concentration. However, only a few are available for the host and are rather general, such as the lipid or protein content, or require incubation, such as respiration and calcification. Moreover, traditional respiration measurements also include symbiont respiration, which may bias the interpretation of the results. Therefore, coral biology is in need of tools to assess host health, and ETSA could be one of these tools.

The long-term effect of the decrease in photosynthetic activity on the respiratory activity and calcification rates was tested on two different coral species: Galaxea fascicularis and Porites cylindrica. Reduced photosynthetic rates were obtained in two ways: corals were maintained under reduced light or exposed to a gradual elevation of temperature. The aim of this experiment is to first better understand the relationship of photosynthesis, respiration and calcification in corals, and second, to investigate the possibility of a direct effect of temperature on mitochondrial ETS, which leads to decreased growth rates. Two different hypothesis were made regarding the mechanisms that lead to a decrease in the respiration potential (ETSA) which both lead to reduced host metabolism (calcification and respiration). The first mechanism would be a decrease in the biomass based on tissue per unit of surface and tissue thickness, resulting in a reduction in the number of active ETS (expressed per unit of surface). The second, caused by damage due to heat stress, would be a decrease in the number of active ETS (expressed in per mg protein, representing the host biomass). Overall, the possibility of using ETSA as an indicator of coral health was tested. 


\section{Materials and Methods}

\section{Coral specimens}

Colonies of Galaxea fascicularis and Porites cylindrica were collected from a coastal region off Okinawa Island, Japan, with permission from the Okinawa Prefecture government (No. 23-7). The P. cylindrica colonies were fractionated to obtain small fragments, and the colony of G. fascicularis was fractionated into single polyps. The fragments were suspended on a nylon thread and maintained for several months in an outdoor aquarium with running seawater at the Sesoko Station, Tropical Biosphere Research Center, University of the Ryukyus, Okinawa, Japan. Micro-colonies, of which the skeleton was entirely covered by tissue, were selected for the experiments.

\section{Experimental design}

Colonies were moved into indoor aquariums with running seawater and maintained under controlled conditions for a minimum of 45 days. Four different conditions were tested, and the different treatments were applied after a minimum of one week to let the corals acclimatize to the indoor conditions. The control treatments corresponded to the natural seawater temperature $\left(24\right.$ to $27{ }^{\circ} \mathrm{C}$ for P. cylindrica and 22 to $26{ }^{\circ} \mathrm{C}$ for G. fascicularis), and an illumination of $300 \mu$ moles of photon s ${ }^{1} \mathrm{~m}^{-2}$ (measured with a 2pi quantum sensor, JFE Advantech, Japan) provided a $12 \mathrm{~h}$ cycle by metal halide lamps. The heat treatment (high temperature stress) was conducted under the same illumination as the control treatment, and the temperature was gradually elevated to reach $32{ }^{\circ} \mathrm{C}$ in the last week of the experiment over the total incubation period at a maximum rate of $1{ }^{\circ} \mathrm{C}$ per week. In the dim treatment (dimmed light), the colonies were incubated under ambient light with a maximum recorded light of $50 \mu$ moles photon $\mathrm{s}^{-1} \mathrm{~m}^{-2}$ and an average of $2.5 \mu$ moles photon $\mathrm{s}^{-1} \mathrm{~m}^{-2}$ in the daytime, and the temperature was the natural seawater temperature (the same as the control). The dark treatment was obtained by covering the aquarium with dark cloth; no measurable light occurred, and the temperature was same as the control. Four micro-colonies of each species were used for each treatment and suspended on a nylon thread. Aeration was continuously provided in all treatments.

\section{Metabolism measurement}

The colonies were enclosed in individual $300-\mathrm{ml}$ vessels directly in their respective aquariums to avoid stress due to manipulation and light regime changes. The water was continuously stirred in the vessels. The incubation was conducted under the appropriate treatment light levels and temperature. The colonies were first incubated under light for $3 \mathrm{~h}$ and then under dark conditions 
for $2 \mathrm{~h}$. For the dark treatment, only a dark incubation was conducted. The dissolved oxygen was measured at the beginning and end of each incubation using an Orion 4-Star pH-DO sensor equipped with an RDO probe (Thermo Scientific). Sub-samples of the incubation water were sampled at the beginning and end of each incubation period and filtered through a $0.45-\mu \mathrm{m}$ membrane filter to measure the total alkalinity. The total alkalinity was determined via titration with $\mathrm{HCl}$ at $0.1 \mathrm{~mol} \mathrm{l}^{-1}$ with a Metrohm titrator (785 DMP titrino). The calcification rates were calculated using the alkalinity anomaly method (Gattuso et al., 1996), and net photosynthesis and respiration were calculated based on the variation in the dissolved oxygen during the light and dark incubation, respectively.

\section{Separation of the host fraction}

The coral tissues were removed using an airbrush with phosphate buffer saline and then homogenized using a Teflon potter homogenizer to break the host cells and release the zooxanthellae. The host and zooxanthellae fraction were separated by centrifugation at $1500 \mathrm{rpm}$ for $20 \mathrm{~min}$.

\section{ETSA measurement}

Electron transport system acitivity was measure as described in Agostini et al. (2013). Five milliliters of the supernatant (the host fraction) was collected and homogenized using a sonicator (Smurt 155 NR-50 M, Microtec Co., Ltd, Funabashi, Japan) at 25\% for $5 \mathrm{~min}$ in the presence of polyvinylpirrolidone $\mathrm{k} 30$ at $1.5 \mathrm{mg} \mathrm{l}^{-1}, \mathrm{MgSO} 4$ at $75 \mu \mathrm{mol} \mathrm{l}^{-1}$, Triton $\mathrm{X}-100$ at $0.20 \%$ and EDTA $2 \mathrm{Na}$ at $10 \mathrm{mmol} \mathrm{l}^{-1}$. The extract was then cleared by centrifugation at 10,000 rpm for $5 \mathrm{~min}$. All the steps were conducted on ice or in a cooling centrifuge at $3{ }^{\circ} \mathrm{C} ; 300 \mu$ of the cell free extract was incubated in the presence of NADH $\left(1.5 \mathrm{mmol} \mathrm{l}^{-1}\right)$, NADPH $\left(0.15 \mathrm{mmol} \mathrm{l}^{-1}\right)$ and tetrazolium salt 2(p-iodophenyl)-3-(p-nitrophenyl)-5-phenyl tetrazolium chloride (INT) (0.4 $\left.\mathrm{mg} \mathrm{1}^{-1}\right)$. The reaction was stopped using 50\% formalin after $20 \mathrm{~min}$, and the absorbance was immediately read at $490 \mathrm{~nm}$. The absorbances were corrected against a turbidity blank (containing $300 \mu$ of the samples, but the reagents were replaced by phosphate buffer saline) and a chemical blank (containing all the reagents but the sample was replaced with phosphate buffer saline). The ETSA were expressed in $\mathrm{mg} \mathrm{O}_{2} \mathrm{~h}^{-1}$ $\mathrm{cm}^{-2}$ using the following formula, where $\mathrm{A}$ is the absorbance at $490 \mathrm{~nm}$, Vs the volume of the sample (in this case $0.3 \mathrm{ml}$ ), $\mathrm{S}$ is the surface of the colony, $\mathrm{Vt}$ is the total volume of the tissue slurry and 7.85 is a factor to convert the increase in absorbance in $20 \mathrm{~min}$ to $\mathrm{mg}$ of $\mathrm{O}_{2} \mathrm{~h}^{-1}$. Alternatively, a similar formula was used where the surface of the skeleton was replaced by the total amount of host protein in the slurry to express the ETSA normalized by the amount of host protein. 


\section{SOD measurements}

The host cells were lysed by sonication in phosphate buffer with $0.05 \%$ Triton X-100. The $\mathrm{Cu} / \mathrm{Zn}$ SOD activity was assayed spectrophotometrically as described by Elstner and Heupel (1976) and Ōyanagui (1984). The standards for activity were prepared using bovine erythrocytic SOD (Sigma) for calibration of the $\mathrm{Cu} / \mathrm{Zn} \mathrm{SOD}$ measurement and using the Mn SOD extracted from buttermilk (Sigma) for the Mn SOD measurement. The Mn SOD was measured by additions of 100 $\mu \mathrm{mol} 1^{-1}$ of KCN in the assay (Beauchamp and Fridovich, 1971). The activities, expressed in nitrate units (NU), were calculated using a logit plot (Kobayashi et al., 1978) and normalized by the units of the host protein.

\section{Zooxanthellae and chlorophyll contents}

The zooxanthellae density was determined by counting cells in the tissue slurry using a hemocytometer (Neubauer modified). A total of 2 to $3 \mathrm{ml}$ of the tissue slurry was filtered on GF/F filters, excess of water removed and placed in $3 \mathrm{ml}$ of $100 \%$ analytical grade methanol. The filters were left to extract in a freezer in the dark for $24 \mathrm{~h}$ and sonicated to ensure complete extraction. The extracts were cleared by filtration using a $0.50-\mu \mathrm{m}$ filter (13JP050AN, Advantec, Japan), and the absorbance was read at $665 \mathrm{~nm}$ and $652 \mathrm{~nm}$. The chlorophyll $a$ concentrations were calculated using the following formula: Chl $a\left(\mu g l^{-1}\right)=16.29 \times A_{665}-8.54 \times A_{652}$ (Ritchie, 2006). The zooxanthellae density and chlorophyll contents were then normalized by the surface area.

\section{Protein and coral surface measurements}

An aliquot from the host fraction obtained after centrifugation at $1500 \mathrm{rpm}$ for 20 min was sonicated and kept in a freezer until measurement. The protein contents were determined by the Bradford assay (Bradford, 1976). The surface of the colonies was determined by the aluminum method (Marsh, 1970) for P. cylindrica and the wax method (Johannes and Wiebe, 1970) for G. fascicularis.

\section{Statistical treatment of the results}

The metabolic rates were normalized by the unit of the surface of the coral skeleton. Enzyme activities, SODs and ETSA were normalized by the host protein contents. The ETSA was also normalized by the unit of the surface for comparison. The amount of chlorophyll $a$ was expressed per unit of surface. All the results were analyzed using the non-parametric Kruskal Wallis test and post-hoc tests using the multiple comparison version (Kruskal Wallis mc), with p-values for 
multiple comparisons adjusted based on the Hochberg method (Hochberg, 1988). Square of the Pearson correlation coefficient among ETSA and the physiological variables and their significance were calculated. All the statistical analyses were conducted with R (Team, 2011) using the agricolae library except for the linear regressions, which were performed with the plotting software qtiplot (Vasilef, n.d.) 


\section{Results}

\section{Coral observations}

All of the corals survived the different treatments. Severe bleaching was obtained for all of the corals in the dark treatment, with P. cylindrica showing a visibly reduced tissue thickness and few expanded polyps. In the dim and heat treatment, more or less severe paling of the corals was observed. Corals in the control treatment showed expanded polyps and bright colors.

\section{Metabolic rates}

Net photosynthesis (Figure 1 A) was significantly affected by treatments in both species (Kruskal Wallis, $\mathrm{n}=4, \mathrm{DF}=3, P$. cylindrica: $\mathrm{p}<0.05$ and $G$. fascicularis: $\mathrm{p}=0.01$ ). For $P$. cylindrica respiration rates in the dim treatments was significantly lower than control (Kruskal Wallis mc, $\mathrm{n}=4, \mathrm{p}=0.03$ ) but the decreased observed under heat treatments was not significant compare to control (Kruskal Wallis mc, $\mathrm{n}=4, \mathrm{p}=0.18$ ). For $G$. fascicularis, a significant reduction in the net photosynthesis rates was found in both treatments compared to the control ((Kruskal Wallis mc, $\mathrm{n}=4, \mathrm{p}=0.180)$.

The treatments significantly decreased the respiration rates (Figure $1 \mathrm{~B}$ ) compared to the control for both species (Kruskal Wallis, $\mathrm{n}=4, \mathrm{DF}=3, \mathrm{p}<0.01$ and $\mathrm{p}<0.01$ for P. cylindrica and $G$. fascicularis, respectively). The most important decrease was observed for the dark and dim treatments. Respiration rates in all treatments were significantly lower than in the control in both species (Kruskal Wallis $\mathrm{mc}, \mathrm{n}=4, \mathrm{p}<0.001$ compared to the control)

Light calcification (Kruskal Wallis, $\mathrm{n}=4, \mathrm{DF}=3$, P.c.: $\mathrm{p}=0.01$, G.f:: $\mathrm{p}<0.01$ ) (Figure $1 \mathrm{C}$ ) and dark calcification (Kruskal Wallis, $\mathrm{n}=4, \mathrm{DF}=3$, P.c.: $\mathrm{p}=0.02$, G.f.: $\mathrm{p}<0.01$ ) (Figure $1 \mathrm{D}$ ) were significantly affected by treatments in both species and the reduction in the treatments was significant compare to control (Kruskal Wallis mc, $n=4, p<0.05$ ) except for the dark calcification rates in the heat treatment which was not different from control. Light calcification was greatly reduced in the dim treatment for both species, and among these specimens, two showed net dissolution for P. cylindrica and one for G. fascicularis. In both the dim and dark treatments, three of the four specimens for each treatment showed a net dissolution in the dark for P. cylindrica. Among all the specimens in the heat treatment, two colonies of P. cylindrica showed net dissolution in the dark, but the average response was not significantly reduced compared to the control. For $G$. fascicularis, the dark calcification rates were low in both the control and the different treatments. One specimen showed net dissolution in the dim treatment and two specimens in the dark 
treatments.

\section{Physiological variables}

The zooxanthellae density (Kruskal Wallis, $\mathrm{n}=4$, $\mathrm{DF}=3$, P.c.: $\mathrm{p}=0.01, G . f: \mathrm{p}<0.01$ ) and chlorophyll $a$ concentration (Kruskal Wallis, $\mathrm{n}=4$, DF $=3$, P.c.: $\mathrm{p}<0.01$, G.f.: $\mathrm{p}<0.01$ ) were significantly decreased compared to the control in both species and in all the treatments compared to the control (Kruskal Wallis mc, $\mathrm{n}=4, \mathrm{p}<0.01$ compared to the control) (Figure 2). The lowest zooxanthellae density for P. cylindrica was observed for the dark treatment. In the heat treatment, the zooxanthellae densities observed were higher but still significantly lower than the control. The chlorophyll $a$ concentration normalized per surface of corals showed a similar pattern. For $G$. fascicularis, the patterns observed were different with the heat treatment, showing average values between the Dim and Dark values for the chlorophyll $a$ but the lowest zooxanthellae density.

The mitochondria electron transport system activity was measured and was normalized by the unit of the surface and the amount of host protein (Figure 3). The interpretation of the results differs and is discussed later. When normalized by the amount of surface, the activities obtained were significantly reduced by treatments for both P. cylindrica (Kruskal Wallis, $\mathrm{n}=4, \mathrm{DF}=3, \mathrm{p}<0.01$ ) and G. fascicularis $(\mathrm{p}<0.01)$. For P. cylindrica, ETSA measured in all three treatments were significantly lower than control (Kruskal Wallis mc, $\mathrm{n}=4, \mathrm{p}<0.05$ ) with the minimum value observed for the dim treatment. In G. fascicularis, posthoc tests revealed that the activities in the dark and heat treatments were significantly reduced compared to the control (Kruskal Wallis mc, $\mathrm{n}=4, \mathrm{p}<0.01$ and $\mathrm{p}<0.01$, respectively) but that the activities in the dim treatment $(87 \%)$ were not significantly different from that of the control (Kruskal Wallis mc, $\mathrm{n}=4, \mathrm{p}=0.31$ ). ETSA, expressed by the amount of host protein, showed that the treatments significantly affected the activities (Kruskal Wallis, $\mathrm{n}=4, \mathrm{DF}=3, \mathrm{p}=0.01$ for P. cylindrica and $\mathrm{p}=0.03$ for G. fascicularis). Significant differences with the control, as indicated by posthoc tests, were only found for the dim treatment for P. cylindrica. The observed reduction in the averaged activities of the specimen in the heat treatment of G. fascicularis ( $91 \%$ of the control) and of P. cylindrica ( $72 \%$ of control) were not significant at the 95\% confidence level (Kruskal Wallis mc, $\mathrm{n}=4, \mathrm{p}=0.25$ and $\mathrm{p}=0.07$, respectively). In addition, the activities in the other treatments did not show a significant difference from the control (Kruskal Wallis $\mathrm{mc}, \mathrm{n}=4, \mathrm{p}>0.1$ ). In G. fascicularis, the only significant difference among treatments for the ETSA normalized by the amount of protein was observed between the Dim and Dark treatments (Kruskal Wallis mc, $\mathrm{n}=4, \mathrm{p}<0.01$ ).

Changes in biomass and the amount of tissue per surface of the skeleton were evaluated using the 
amount of protein per surface (Figure 4). In both species, the maximum values were observed for the control treatment and a significant effect of the treatments was observed (Kruskal Wallis, $\mathrm{n}=4$, $\mathrm{DF}=3, \mathrm{p}<0.01$ for $P$. cylindrica and $\mathrm{p}=0.01$ for $G$. fascicularis). In P. cylindrica, the minimum value was obtained for the Dim treatment and a similar value was obtained for the dark. The amount of protein in the heat treatment was not significantly reduced compared to the control at the $95 \%$ confidence level (Kruskal Wallis $\mathrm{mc}, \mathrm{n}=4, \mathrm{p}=0.06$ ). For $G$. fascicularis, the minimum value was observed for the heat treatment, and the protein contents in the dim and dark treatment were significantly lower than the control.

Mitochondrial electron Transport system activity, normalized by the amount of surface, show a positive correlation with the different metabolic rates and physiological variable (Figure 5). The correlations were all significant $(\mathrm{n}=32$ or $24, \mathrm{df}=30$ or $22, \mathrm{p}<0.01)$ with the strongest observed between light calcification and ETSA, $r^{2}=0.75$. A positive correlation of ETSA with the amount of protein was observed with coefficient of correlation of 0.61 .

Two different superoxide dismutase activities were measured (Figure 6): Manganese Superoxide dismutase (Mn SOD) and Copper Zinc Superoxide dismutase (Cu/Zn SOD). The Mn SOD activities were minimal in the control treatment for both species. They significantly increased in all other treatments, except for the dark treatment (Kruskal Wallis, $n=4, D F=3, p<0.01$ ), compared to the control, with a maximum occurring for the heat treatment. No significant effect of the treatments was observed for $\mathrm{Cu} / \mathrm{Zn}$ SOD for $G$. fascicularis (Kruskal Wallis, $\mathrm{n}=4, \mathrm{DF}=3, \mathrm{p}=0.24$ ) which show generally lower activities than P. cylindrica. For P. cylindrica, the activity of Cu/Zn SOD was significantly affected by the treatments (Kruskal Wallis, $n=4, D F=3, p=0.02$ ), with significantly higher values than the control in the Dim treatments.

\section{Discussion}

Both methods, light depletion and heat stress caused bleaching in the two species studied, as shown by the significant decrease in zooxanthellae densities and chlorophyll contents, which are parameters that are typically used to assess bleaching (Hoegh-Guldberg and Smith, 1989). Simultaneous to bleaching, reduced photosynthesis and calcification rates were observed, as is commonly observed for bleached corals (Abramovitch-Gottlib et al., 2002; Colombo-Pallotta et al., 2010; Foster et al., 2014; Marshall, 1996). All metabolic rates: net photosynthesis, dark respiration, and light and dark calcification, as expressed by the unit of the surface, were significantly affected by the different treatments in both species. Overall, the most visible effects were caused by the dark treatments for which severely reduced metabolic rates were observed. This treatment is however not 
realistic in nature and only provide elements to understand the physiology of corals. More variable responses were obtained for the heat and dim treatments. Low light level (Dim treatment) incubation of corals for over one month is also an extreme condition, but not unrealistic. It led to an important decrease in metabolic rates, including photosynthesis and calcification. Dark calcification was greatly reduced in the light depleted treatments, with net dissolution often observed. For the respiration rates, the observed decrease in all treatments compared to the control may have two different explanations that are not exclusive: respiration is limited by the availability of the substrate to oxidize and the number of working electron transport systems and enzymes required is decreased. It is interesting to note that for G. fascicularis, while the zooxanthellae density was lower in the heat treatment than in the dark and dim treatments, the metabolic rates of the corals in the heat treatment were still higher, which indicated a strong limitation of zooxanthellae by the energy light available and therefore a reduction in the production of available photosynthetate. The type of zooxanthellae typically found in G. fascicularis and P. cylindrica is known to differ possibly explaining the difference observed in the effect of the treatments. On the one hand, G. fascicularis has been shown to be associated with $\mathrm{C} 1$ or $\mathrm{C} 3$ zooxanthellae, $\mathrm{C} 1$ being known to be adapted to low light level (Oppen et al, 2005) but sensitive to thermal stress (Baird et al., 2010). Contrasting with P. cylindrica which could, as other species of the genus Porites in the Asia-Pacific region, be associated with the thermo-tolerant zooxanthellae from the clade C15 (D'Angelo et al., 2015).

The relationship between photosynthesis and calcification and the enhancement of calcification in the light has long been known (Goreau, 1959) and widely reviewed (Gattuso et al., 1996; Kinsey, 1978); however, the exact mechanism of the relation has not been determined (Allemand et al., 2004). The respiration rates also show a strong relation with photosynthesis. In the experiment reported here, the decrease in photosynthesis was always associated with decreased, sometimes severely decreased, as in the light depletion treatment, respiration rates. In a previous paper, the respiration limited calcification model was introduced. This model is similar to the transcalcification model (McConnaughey, 1997), but with a stronger focus on the role of respiration. This model implies that photosynthesis provides the substrates required for respiration, which then provide the energy required for calcification (Agostini et al., 2013). In this study, the use of artificially bleached corals, allowed testing whether the model is still valid for a wider range of respiration rates. In the most extreme case (dark treatment), respiration was strongly limited by the availability of substrate and calcification was minimal or even resulted in net dissolution, which suggests that respiration may have limited calcification. The effects of the treatments on the light and dark calcification ratios were not clear for P. cylindrica because of the important variation due 
to the extremely low dark calcification rates. In G. fascicularis, the ratio decrease from 3 in the control treatment to less than 1 in the dim and heat treatments showed that the enhancement of calcification by light was removed due to the lack of photosynthesis and therefore supports the hypothesis that this enhancement is due to the photosynthetic activity.

A generally accepted model for bleaching through heat stress involves the production of reactive oxygen species (ROS) (Downs et al., 2002). Typically, zooxanthellae and their photosynthetic apparatus are associated with the production of ROS; however, mitochondria and their electron transport systems are known to produce ROS under heat stress, at least in plants (Taylor et al., 2004), and more damaged mitochondria were observed in heated stressed cnidarian, damages that may have been caused by ROS (Dunn et al., 2012). In this paper, two different superoxide dismutase activities in the host tissues were measured: The copper/Zinc superoxide dismutase $(\mathrm{Cu} / \mathrm{Zn} \mathrm{SOD})$ which is a cytoplasmic SOD and the Manganese superoxide dismutase (Mn SOD) which is found strictly in the mitochondria. The following hypothesis were made to assess the origin of the ROS produced under stress. In the case ROS mainly originates from the zooxanthellae due to the damage to their photosystems, the host $\mathrm{Cu} / \mathrm{Zn}$ SOD should increase the most, and in the case ROS are mainly produced in the host mitochondria, then the Mn SOD should increase the most. In the last case, where mitochondria is the main source of ROS for coral host under stress, the ROS could result in damage to the host mitochondrial electron transport systems. The Mn SOD activity was found to significantly increase in the heat treatment in both species. The $\mathrm{Cu} / \mathrm{Zn} \mathrm{SOD}$ activity increased in both the $\operatorname{dim}$ and heat treatments in P. cylindrica, but was not increased in $G$. fascicularis. These results suggest that ROS were produced in the host mitochondria and that damage to the respiratory apparatus could have occurred. In the light depletion specimens, the $\mathrm{Mn}$ SOD and, in some cases, $\mathrm{Cu} / \mathrm{Zn}$ SOD activities increased, but not as much as in the heat treated specimens. The mechanism behind the increase of SOD under depletion of light, and therefore possible ROS production in the host, remains unknown. It is usually considered that light is required for the production of ROS in zooxanthellae (Lesser, 1996). Thus, zooxanthellae may not be the source of ROS under light depletion for some coral species, but the mitochondria may be.

Because the ROS production increase may have been higher under heat stress than in the light depletion treatment, it is assumed that the decrease in the respiration rates observed is due to both damage to the respiratory system and substrate limitation in the heat treatment, but mainly by substrate limitation in the light depletion treatments. To investigate this, the activity of the electron transport system (ETSA) using the INT methods was measured (Agostini et al., 2013; Packard, 1971). The interpretation of the ETSAs in the different treatments changes with the normalization 
used. To show a decrease in ETSA due to ROS damage, the activities normalized by the amount of host protein could be used with the assumption that they represent the host biomass and, consequently, the total number of ETS. While the treatment significantly affected the ETSA normalized by protein for both species, only P. cylindrica under the dim treatment was significant decreased compared to the control. For G. fascicularis only the activities in the dim and dark treatment were significantly different. This result indicates that while possible direct damage to the mitochondrial electron transport system using the INT methods could be observed, the experiment could not sufficiently detect the decrease in ETSA for multiple comparison. Moreover, a more severe decrease was expected in the heat stress treatment than in the light depletion treatment, as the Mn SOD activities were higher in the heat treatment, but that was not always observed. One explanation may be that the production of ROS in the mitochondria damages part of the enzymes/transporters lower in the transporter chain. The tetrazolium salt INT is reduced to formazan by the cytochrome $\mathrm{b}$ - ubiquinone complex and before the complex III, which means that damage further down the chain may not always lead in decreased ETSA.

Electron transport system activity normalized by the surface of the host can be used as an easy to measure overall health (metabolism) indicator for the host. It has already been used for this purpose with other organisms (Finlay et al., 1983; Simcic, 2004) and is typically used to estimate the respiration rates of plankton (Arístegui and Montero, 1995; Bamstedt, 1980; Packard, 1971) or the overall metabolism of meiofauna (Cammen and Corwin, 1990; Olanczukneyman and Vosjan, 1977; Wada et al., 2012). Decreased ETSA in the different treatments and a strong correlation with metabolic rates was observed, confirming the previous results obtained with the same methods (Agostini et al., 2013). The experiment conducted consisted of long-term exposure to the treatments. This led to a change in tissue biomass, which was shown by a reduction in the amount of protein per surface for the different treatments. Decreased tissue biomass: essential constituent of coral tissue and energetic reserve such as proteins, and lipids, is typical for bleached coral (Fitt et al., 2000; Rodrigues and Grottoli, 2007; Porter et al., 1989; Szmant and Gassman, 1990). However, more than just a decrease in the reserve available to the coral host, this result show that the observed decrease in biomass is associated with a decrease in ETSA. The reduction in ETSA could be due to a decrease in the number of mitochondria and therefore a decrease in the number of ETS. Therefore, ETSA can incorporate both the change in biomass or tissue thickness and the direct effect of stress on the mitochondrial electron transport system.

In conclusion, long-term exposure to heat stress or light depletion leads to bleaching and reduced photosynthesis rates. The assumed reduced availability of the substrate for respiration results in the 
reduction of respiration and ETSA and, ultimately, to a reduction of calcification through the limitation of available energy. The increase in Mn SOD, which may correlate with the production of ROS in the mitochondria, was associated with decreased ETSA normalized by the host protein, which indicated damage to the mitochondrial electron transport system. More specific methods will be required, such as the measurement of the activities of the different complexes, to distinguished which step and enzymes are impaired by the different stresses. The measurement of ETSA by the INT methods is a simple and relevant way to assess the potential metabolism and therefore the health of corals and could be applied in field studies to provide a long needed tool to assess the state of the host animal in corals.

\section{Acknowledgments}

This research was supported by the International Research Hub Project for Climate Change and Coral Reef/Island Dynamics at the University of the Ryukyus. The authors are grateful to comments of anonymous reviewers and of the editor which greatly improve this manuscript.

\section{References}

Abramovitch-Gottlib, L., Katoshevski, D., Vago, R., 2002. A computerized tank system for studying the effect of temperature on calcification of reef organisms. J. Biochem. Biophys. Methods 50, 245-252. doi:10.1016/S0165-022X(01)00236-6

Agostini, S., Fujimura, H., Fujita, K., Suzuki, Y., Nakano, Y., 2013. Respiratory electron transport system activity in symbiotic corals and its link to calcification. Aquat. Biol. 18, 125-139. doi:10.3354/ab00496

D’Angelo, C., Hume, B.C.C., Burt, J., Smith, E.G., Achterberg, E.P., Wiedenmann, J., 2015. Local adaptation constrains the distribution potential of heat-tolerant Symbiodinium from the Persian/Arabian Gulf. ISME J. doi:10.1038/ismej.2015.80

Al-Horani, F.A., Tambutté, É., Allemand, D., 2007. Dark calcification and the daily rhythm of calcification in the scleractinian coral, Galaxea fascicularis. Coral Reefs 26, 531-538. doi:10.1007/s00338-007-0250-x

Allemand, D., Ferrier-Pagès, C., Furla, P., Houlbrèque, F., Puverel, S., Reynaud, S., Tambutté, É., Tambutté, S., Zoccola, D., 2004. Biomineralisation in reef-building corals: from molecular mechanisms to environmental control. Comptes Rendus Palevol 3, 453-467. doi:10.1016/j.crpv.2004.07.011

Arístegui, J., Montero, M.F., 1995. The relationship between community respiration and ETS activity in the ocean. J. Plankton Res. 17, 1563-1571. doi:10.1093/plankt/17.7.1563

Baird, A.H., Bhagooli, R., Nonaka, M., Yakovleva, I., Yamamoto, H.H., Hidaka, M., Yamasaki, H., 2010. Environmental controls on the establishment and development of algal symbiosis in corals, in: Proceedings of the 11th International Coral Reef Symposium. Presented at the 11th International Coral Reef Symposium, Fort Lauderdale, FL, USA, pp. 108-112.

Bamstedt, U., 1980. ETS activity as an estimator of respiratory rate of zooplankton populations. The significance of variations in environmental factors. J. Exp. Mar. Biol. Ecol. 42, 267-283.

Barnes, D.J.D., Chalker, B.E.B., 1990. Calcification and photosynthesis in reef-building corals and algae, in: Dubinsky, Z. (Ed.), Ecosystems of the World. Elsevier Science Publisher, pp. 109- 
131.

Beauchamp, C., Fridovich, I., 1971. Superoxide dismutase: Improved assays and an assay applicable to acrylamide gels. Anal. Biochem. 44, 276-287.

Bradford, M., 1976. A rapid and sensitive method for the quantitation of microgram quantities of protein utilizing the principle of protein-dye binding. Anal. Biochem. 72, 248-254. doi:10.1016/0003-2697(76)90527-3

Cammen, L., Corwin, S., 1990. Electron transport system (ETS) activity as a measure of benthic macrofaunal metabolism. Mar. Ecol. Prog. Ser. 65, 171-182.

Chalker, B.E., Taylor, D.L., 1975. Light-Enhanced Calcification, and the Role of Oxidative Phosphorylation in Calcification of the Coral Acropora cervicornis. Proc. R. Soc. B Biol. Sci. 190, 323-331. doi:10.1098/rspb.1975.0096

Cohen, A., Holcomb, M., 2009. Why Corals Care About Ocean Acidification: Uncovering the Mechanism. Oceanography 22, 118-127. doi:10.5670/oceanog.2009.102

Colombo-Pallotta, M.F., Rodríguez-Román, A., Iglesias-Prieto, R., 2010. Calcification in bleached and unbleached Montastraea faveolata: evaluating the role of oxygen and glycerol. Coral Reefs 29, 899-907. doi:10.1007/s00338-010-0638-x

Downs, C. a, Fauth, J.E., Halas, J.C., Dustan, P., Bemiss, J., Woodley, C.M., 2002. Oxidative stress and seasonal coral bleaching. Free Radic. Biol. Med. 33, 533-43.

Dunn, S.R., Pernice, M., Green, K., Hoegh-Guldberg, O., Dove, S.G., 2012. Thermal stress promotes host mitochondrial degradation in symbiotic cnidarians: are the batteries of the reef going to run out? PloS One 7, e39024.

Elstner, E.F., Heupel, A., 1976. Inhibition of nitrite formation from hydroxylammoniumchloride: A simple assay for superoxide dismutase. Anal. Biochem. 70, 616-620.

Finlay, B., Span, A., Ochsenbeingattlen, C., 1983. Influence of physiological state on indices of respiration rate in protozoa. Comp. Biochem. Physiol. A Physiol. 74, 211-219. doi:10.1016/0300-9629(83)90590-X

Fitt, W.K., McFarland, F.K., Warner, M.E., Chilcoat, G.C., 2000. Seasonal patterns of tissue biomass and densities of symbiotic dinoflagellates in reef corals and relation to coral bleaching. Limnol. Oceanogr. 45, 677-685. doi:10.4319/lo.2000.45.3.0677

Foster, T., Short, J.A., Falter, J.L., Ross, C., McCulloch, M.T., 2014. Reduced calcification in Western Australian corals during anomalously high summer water temperatures. J. Exp. Mar. Biol. Ecol. 461, 133-143. doi:10.1016/j.jembe.2014.07.014

Furla, P., Galgani, I., Durand, I., Allemand, D., 2000. Sources and mechanisms of inorganic carbon transport for coral calcification and photosynthesis. J. Exp. Biol. 203, 3445-57.

Gattuso, J., Pichon, M., Delesalle, B., Canon, C., Frankignoulle, M., 1996. Carbon fluxes in coral reefs. I. Lagrangian measurement of community metabolism and resulting air-sea $\mathrm{CO} 2$ disequilibrium. Mar. Ecol. Prog. Ser. 145, 109-121. doi:10.3354/meps145109

Glynn, P.., Imai, R., Sakai, K., Nakano, Y., Yamazato, K., 1992. Experimental Responses of Okinawan (Ryukyu Islands, Japan) Reef Corals to High Sea Temperature and UV Radiation, in: Richmond, R.H. (Ed.), Proceedings of the Seventh International Coral Reef Symposium. University of Guam Press, Guam, pp. 27-37.

Goreau, T.F., 1959. The physiology of skeleton formation in corals. I. A method for measuring the rate of calcium deposition by corals under different conditions. Biol. Bull. 116, 59-75.

Higuchi, T., Agostini, S., Casareto, B.E., Yoshinaga, K., Suzuki, T., Nakano, Y., Fujimura, H., Suzuki, Y., 2013. Bacterial enhancement of bleaching and physiological impacts on the coral Montipora digitata. J. Exp. Mar. Biol. Ecol. 440, 54-60. doi:10.1016/j.jembe.2012.11.011

Higuchi, T., Fujimura, H., Hitomi, Y., Arakaki, T., Oomori, T., Suzuki, Y., 2010. Photochemical formation of hydroxyl radicals in tissue extracts of the coral Galaxea fascicularis. Photochem. Photobiol. 86, 1421-1426. doi:10.1111/j.1751-1097.2010.00802.x

Hochberg, Y., 1988. A sharper Bonferroni procedure for multiple tests of significance. Biometrika 
75, 800-802. doi:10.1093/biomet/75.4.800

Hoeghguldberg, O., Smith, G., 1989. The effect of sudden changes in temperature, light and salinity on the population density and export of zooxanthellae from the reef corals Stylophora pistillata Esper and Seriatopora hystrix Dana. J. Exp. Mar. Biol. Ecol. 129, 279-303. doi:10.1016/0022-0981(89)90109-3

Johannes, R.E., Wiebe, W.J., 1970. Method for determination of coral tissue biomass and composition. Limnol. Oceanogr. 15, 822-824.

Jones, R.J., Hoegh-Guldberg, O., Larkum, A.W.D., Schreiber, U., 1998. Temperature-induced bleaching of corals begins with impairment of the $\mathrm{CO} 2$ fixation mechanism in zooxanthellae. Plant Cell Environ. 21, 1219-1230. doi:10.1046/j.1365-3040.1998.00345.x

Kinsey, D., 1985. Metabolism, calcification and carbon production, in: Proc 5th Int Coral Reef Congr, Tahiti. International Coral Reefs Society, Tahiti, pp. 4:515-526.

Kinsey, D.W.D.W., 1978. Alkalinity changes and coral reef calcification. Limnol. Oceanogr. 23, 989-991. doi:10.4319/10.1978.23.5.0989

Kobayashi, Y., Okahata, S., Tanabe, K., Usui, T., 1978. Use of logit paper in determination of superoxide dismutase activity in human blood cells. J. Immunol. Methods 24, 75-78.

Lesser, M.P., 1996. Elevated temperatures and ultraviolet radiation cause oxidative stress and inhibit photosynthesis in symbiotic dinoflagellates. Limnol. Oceanogr. 271-283.

Marshall, A.T., 1996. Calcification in Hermatypic and Ahermatypic Corals. Science 271, 637-639. doi:10.1126/science.271.5249.637

Marsh, J.A., 1970. Primary Productivity of Reef-Building Calcareous Red Algae. Ecology 51, 255. doi:10.2307/1933661

McConnaughey, T., 1997. Calcification generates protons for nutrient and bicarbonate uptake. Earth-Sci. Rev. 42, 95-117.

Moya, A., Tambutté, S., Tambutté, E., Zoccola, D., Caminiti, N., Allemand, D., 2006. Study of calcification during a daily cycle of the coral Stylophora pistillata: implications for "lightenhanced calcification". J. Exp. Biol. 209, 3413-9. doi:10.1242/jeb.02382

Olanczukneyman, K., Vosjan, J., 1977. Measuring respiratory electron-transport-system activity in marine sediment. Neth. J. Sea Res. 11, 1-13. doi:10.1016/0077-7579(77)90017-5

Ōyanagui, Y., 1984. Reevaluation of assay methods and establishment of kit for superoxide dismutase activity. Anal. Biochem. 142, 290-296. doi:10.1016/0003-2697(84)90467-6

van Oppen, M.J.H., Mahiny, A.J., Done, T.J., 2005. Geographic distribution of zooxanthella types in three coral species on the Great Barrier Reef sampled after the 2002 bleaching event. Coral Reefs 24, 482-487. doi:10.1007/s00338-005-0487-1

Packard, T., 1971. The measurement of respiratory electron-transport activity in marine phytoplankton. J. Mar. Res. 29, 235-244.

Porter, J.W., Fitt, W.K., Spero, H.J., Rogers, C.S., White, M.W., 1989. Bleaching in reef corals: Physiological and stable isotopic responses. PNAS 86, 9342-9346.

Ritchie, R.J., 2006. Consistent sets of spectrophotometric chlorophyll equations for acetone, methanol and ethanol solvents. Photosynth. Res. 89, 27-41. doi:10.1007/s11120-006-9065-9

Rodrigues, L.J., Grottoli, A.G., 2007. Energy reserves and metabolism as indicators of coral recovery from bleaching. Limnol. Oceanogr. 52, 1874-1882. doi:10.4319/1o.2007.52.5.1874

Simcic, T., 2004. Respiratory electron transport system (ETS) activity as an estimator of the thermal tolerance of two Daphnia hybrids. J. Plankton Res. 26, 525-534. doi:10.1093/plankt/fbh056

Szmant, A.M., Gassman, N.J., 1990. The effects of prolonged "bleaching" on the tissue biomass and reproduction of the reef coral Montastrea annularis. Coral Reefs 8, 217-224.

doi:10.1007/BF00265014Taylor, N.L., Day, D.A., Millar, A.H., 2004. Targets of stressinduced oxidative damage in plant mitochondria and their impact on cell carbon/nitrogen metabolism. J. Exp. Bot. 55, 1-10. doi:10.1093/jxb/erh001

Team, R.D.C., 2011. R: A Language and Environment for Statistical Computing. R Foundation for 
Statistical Computing, Vienna, Austria.

Tolleter, D., Seneca, F.O., DeNofrio, J.C., Krediet, C.J., Palumbi, S.R., Pringle, J.R., Grossman, A.R., 2013. Coral Bleaching Independent of Photosynthetic Activity. doi:10.1016/j.cub.2013.07.041

Vasilef, I., n.d. QtiPlot.

Wada, M., Suzuki, S., Nara, T., Umezawa, Y., Shimanaga, M., Matsuoka, K., Nakata, H., 2012. Microbial community respiration and structure of dead zone sediments of Omura Bay, Japan. J. Oceanogr. 68, 857-867. doi:10.1007/s10872-012-0136-6

Warner, M.E., Fitt, W.K., Schmidt, G.W., 1999. Damage to photosystem II in symbiotic dinoflagellates: A determinant of coral bleaching. Proc Natl Acad Sci U S A 96, 8007-8012.

Yonge, C.M. (Charles M.S., Yonge, C.M. (Charles M., History), B.M. (Natural, (1928-29), G.B.R.E., 1930. Studies on the physiology of corals. V. The effect of starvation in light and in darkness on the relation- ship between corals and zooxanthellae., in: Great Barrier Reef Expedition, 1928-29 : Scientific Reports. Printed by order of Trustees of the British Museum, London :, pp. 177-211. 


\section{Figures}

Figure 1 : Net photosynthetic rates (A), respiration rates (B), light calcification rates (C) and dark
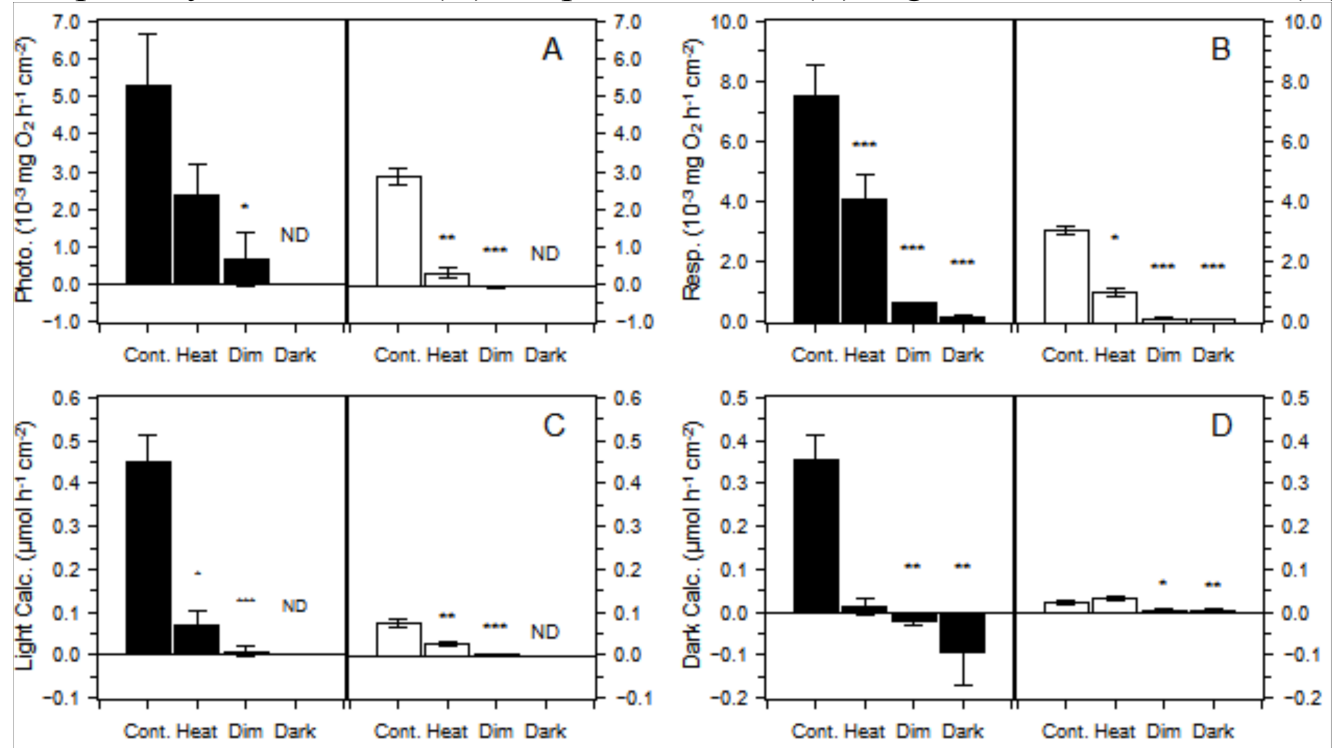

calcification rates (D) in P. cylindrica (black) and G. fascicularis (white). The error bars show the standard error $(\mathrm{n}=4)$, and the star marks showed significant difference $(* \mathrm{p}<0.05$; $* * \mathrm{p}<0.001 ; * * * \mathrm{p}<0.0001)$ with the control after multiple comparisons with the Kruskal Wallis and p-values adjusted by the Hochberg method. ND: not measured. 

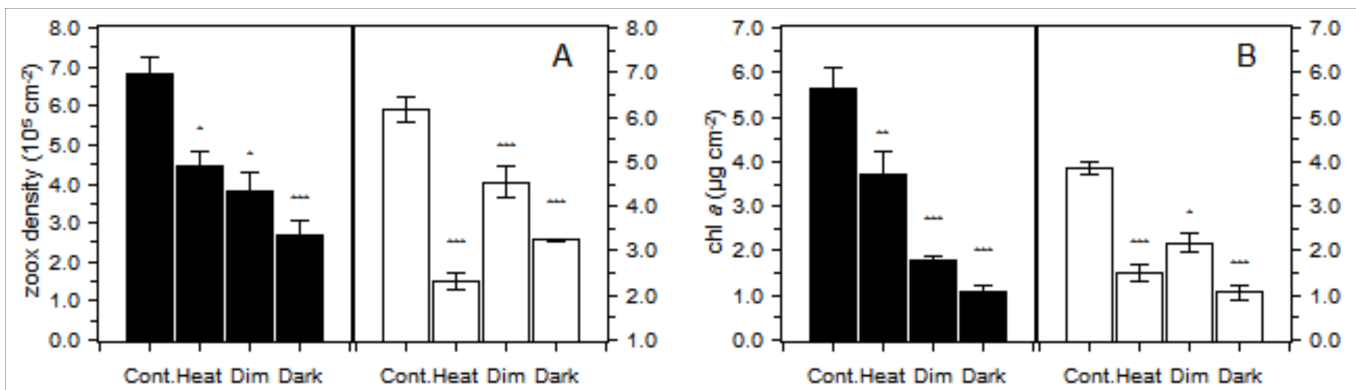

Figure 2 : Zooxanthellae density (A) and chlorophyll $a$ concentration (B) in P. cylindrica (black) and G. fascicularis (white). The error bars show the standard error $(\mathrm{n}=4)$, the star marks showed significant difference $(* \mathrm{p}<0.05 ; * * \mathrm{p}<0.001 ; * * * \mathrm{p}<0.0001)$ with the control after multiple comparisons with the Kruskal Wallis and p-values adjusted by the Hochberg method. 

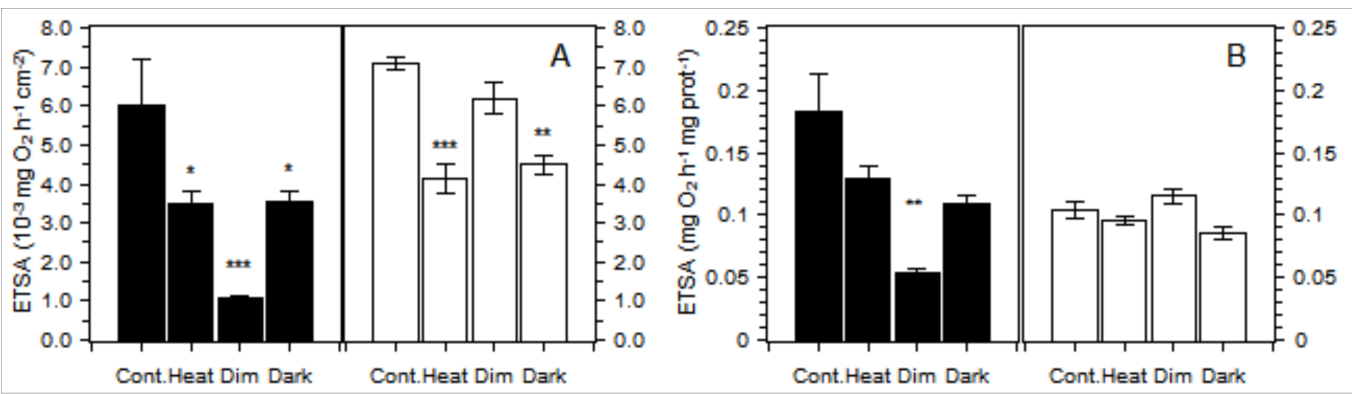

Figure 3: Mitochondrial electron transport activity (ETSA) normalized by the unit of the skeleton surface (A) and ETSA normalized by the milligrams of host protein (B) in P. cylindrica (black) and G. fascicularis (white). The error bars show the standard error $(\mathrm{n}=4)$, and the star marks showed significant difference $(* \mathrm{p}<0.05 ; * * \mathrm{p}<0.001 ; * * * \mathrm{p}<0.0001)$ with the control after multiple comparisons with the Kruskal Wallis and p-values adjusted by the Hochberg method. 


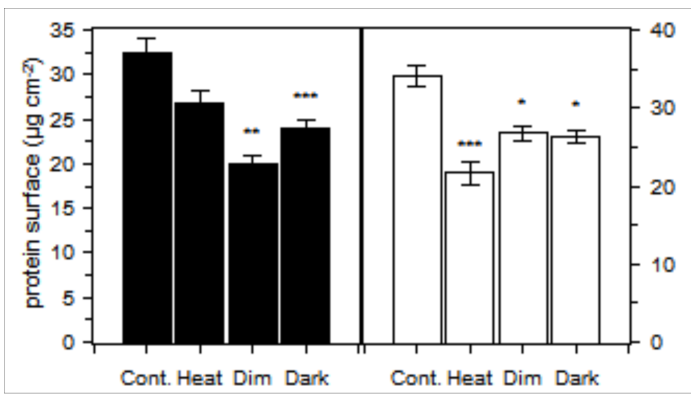

Figure 4: Amount of the host protein per unit of skeleton surface in P. cylindrica (black) and $G$. fascicularis (white). The error bars show the standard error $(n=4)$, and the star marks showed significant difference $(* \mathrm{p}<0.05 ; * * \mathrm{p}<0.001 ; * * * \mathrm{p}<0.0001)$ with the control after multiple comparisons with the Kruskal Wallis and p-values adjusted by the Hochberg method. 


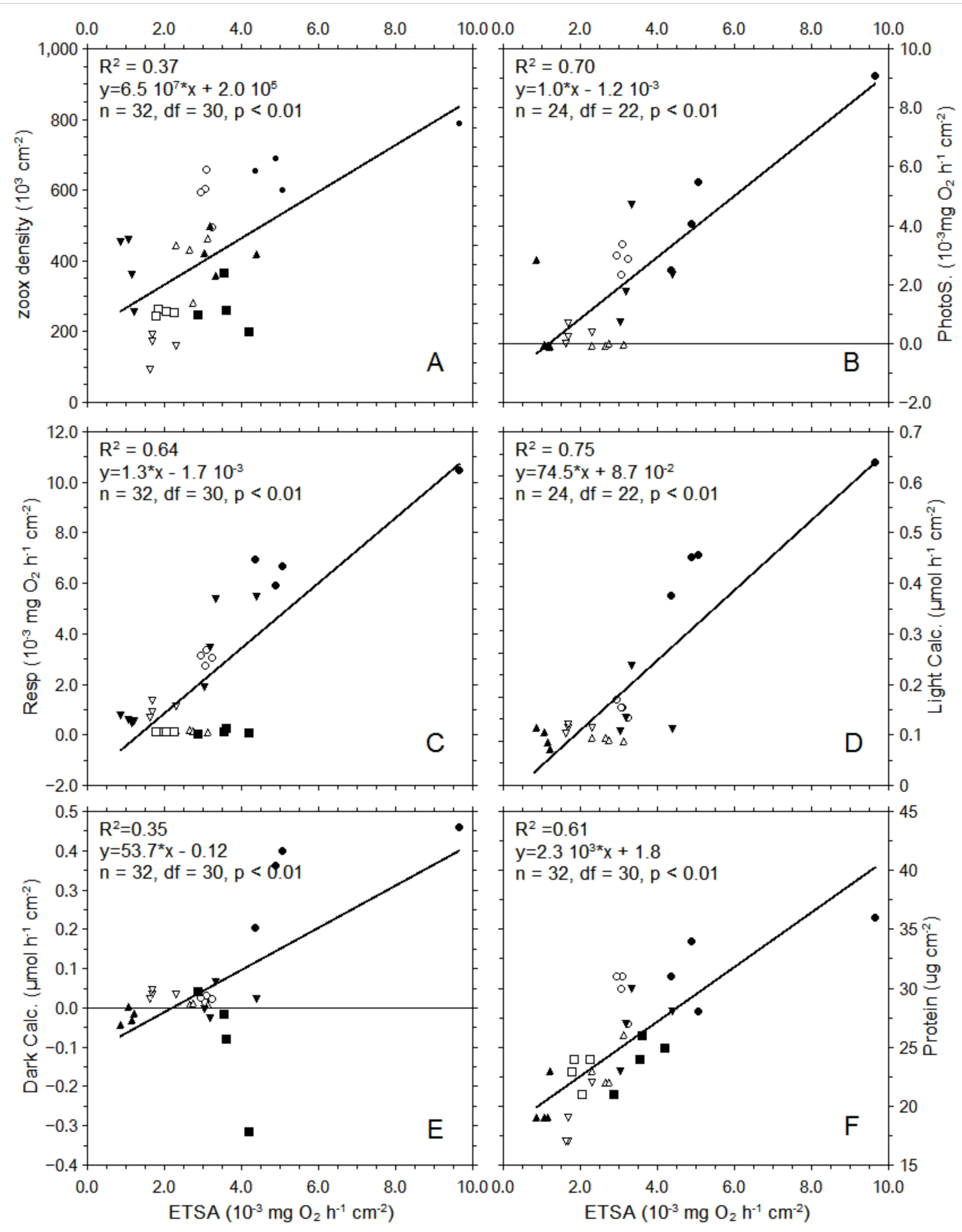

Figure 5: Correlations of ETSA with zooxanthellae density (A), photosynthesis (B), respiration (C), light calcification (D), dark calcification (E) and host protein (F). The coefficient of correlation for the linear regression $\left(\mathrm{R}^{2}\right)$, equation of the relation and statistical significance are indicated on the respective plots. Black represents data from P. heronensis and white from G. fascicularis. The 
different treatments: Control, Heat, Dim and Dark are represented by the symbols: ellipse, down triangle, up triangle and square, respectively. 


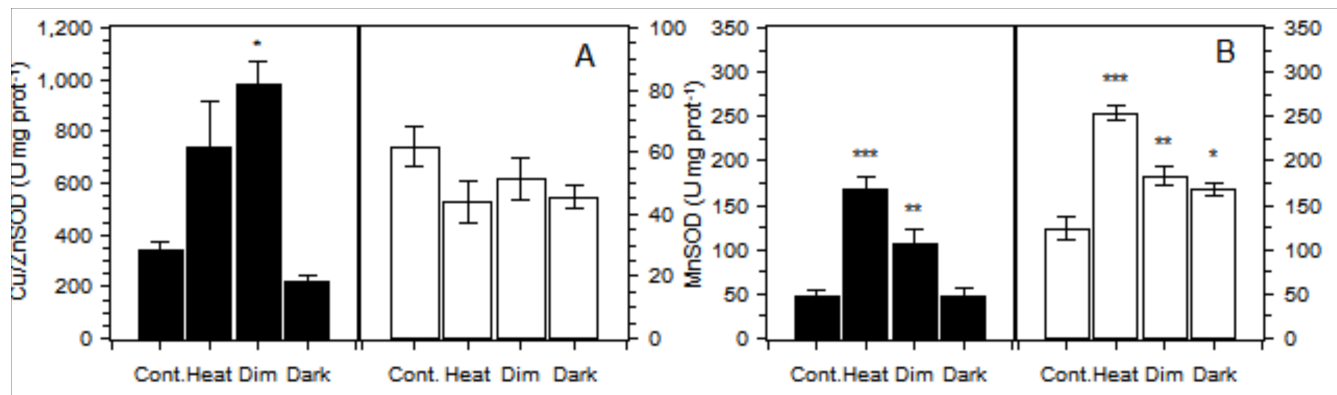

Figure $6: \mathrm{Cu} / \mathrm{Zn}$ SOD activities (A) and MnSOD activities (B) in P. cylindrica (black) and G. fascicularis (white). The error bars show the standard error $(n=4)$, and the star marks showed significant difference $(* \mathrm{p}<0.05 ; * * \mathrm{p}<0.001 ; * * * \mathrm{p}<0.0001)$ with the control after multiple comparisons with Kruskal Wallis and p-values adjusted by the Hochberg method. 